\section{Pan-neural Prospero terminates cell proliferation during Drosophila neurogenesis}

\author{
Ling $\mathrm{Li}^{1}$ and Harald Vaessin ${ }^{1-3}$ \\ ${ }^{1}$ Department of Molecular Genetics and ${ }^{2}$ Neurobiotechnology \\ Center and Comprehensive Cancer Center, Ohio State \\ University, Columbus, Ohio 43210 USA
}

Organogenesis requires coordination between developmental specific regulators and genes governing cell proliferation. Here we show that Drosophila prospero encodes a critical regulator of the transition from mitotically active cells to terminal differentiated neurons. Loss of pros results in aberrant expression of multiple cellcycle regulatory genes and ectopic mitotic activity. In contrast, ectopic pros expression causes transcriptional suppression of multiple cell-cycle regulatory genes and premature termination of cell division. pros activity, hence, provides a critical regulatory link between neuronal lineage development and transcriptional regulation of cell cycle regulatory genes.

Received October 26, 1999; revised version accepted December 8, 1999.

Proliferation and differentiation processes are in general mutually exclusive. As in other organogenic processes, neuronal lineage cells must exit the mitotically active state before entering terminal differentiation. Termination of cell proliferation requires functional interactions between tissue-specific genes and genes governing cell division (Edgar and Lehner 1996; Zavitz and Zipursky 1997).

During neurogenesis in Drosophila embryos, neuronal precursors divide asymmetrically, giving rise to two daughter cells with distinct cell fates and mitotic potential. In the central nervous system (CNS), neuroblasts divide to produce another neuroblast and a ganglion mother cell (GMC), which will divide once more to generate two neurons or glia (Jan and Jan 1998). prospero (pros) encodes an evolutionarily conserved atypical homeodomain protein (Pros) that is expressed in all neuronal lineages (Chu-Lagraff et al. 1991; Doe et al. 1991; Vaessin et al. 1991; Matsuzaki et al. 1992). Loss of pros function is associated with developmental defects in neuronal lineages (Doe et al. 1991; Vaessin et al. 1991), longitudinal glial cell differentiation (Jacobs 1993), and eye development (Kauffmann et al. 1996). Pros protein and RNA show striking cellular distribution pattern during neurogenesis (Hirata et al. 1995; Knoblich et al. 1995; Spana and Doe 1995; Jan and Jan 1998). In neuroblasts

[Key Words: Drosophila; prospero; cell proliferation; neurogenesis] ${ }^{3}$ Corresponding author.

E-MAIL vaessin.1 osu.edu; FAX (614) 292-5379. and sensory organ precursors, Pros is asymmetrically localized to the cytoplasmic membrane (Hirata et al. 1995; Knoblich et al. 1995; Spana and Doe 1995). In the case of neuroblasts, Pros is distributed exclusively to one daughter cell, the GMC, where it translocates from the cytoplasm into the nucleus. The translocation of Pros into GMC nuclei coincides with a critical developmental checkpoint-the decision to exit from the mitotically active state to undergo terminal differentiation (de Nooij et al. 1996; Lane et al. 1996). The asymmetric localization and distribution of Pros in this process parallels the regulatory events closely, which ensure that cell proliferation and differentiation occur in the appropriate cells. In this study we analyze the involvement of the Drosophila melanogaster gene pros in the regulation of mitotic activity during CNS development. Our data show that pan-neural Pros is a critical regulator for the developmental transition of mitotically active cells to terminal differentiation.

\section{Results and Discussion \\ Loss of pros function results in increased mitotic activity}

To determine whether Pros activity is required for proper regulation of cell proliferation during embryonic development, we analyzed mitotic activity in the developing nervous system of homozygous pros loss-of-function mutant embryos, using three independently isolated amorphic pros alleles (Vaessin et al. 1991; Salzberg et al. 1994). Cells entering and progressing through S phase were identified by S-phase-specific Histone 1A RNA expression (Hassan and Vaessin 1997) and BrdU incorporation (Bodmer et al. 1989). Mitotic cells were identified with the M-phase-specific marker, anti-phospho Histone H3 (Upstate Biotechnology). Using these assays, we observed high levels of additional S- and M-phase activity in late-stage pros homozygous mutant embryos relative to wild-type embryos (Fig. 1). Although substantial defects are evident during axonal outgrowth (Doe et al. 1991; Vaessin et al. 1991), developmental landmarks of neurogenesis, such as initiation of axonal outgrowth, still occur at appropriate stages in pros mutant embryos. Therefore, the observed increased mitotic activity in pros mutant embryos appears not to result from a general delay in the timing of neuronal lineage development, but rather from a loss-of-cell cycle control.

Despite ectopic mitotic activity in pros loss-of-function mutant embryos, no substantial hyperplasia of the nervous system was evident in embryonic CNS. We speculate that compensatory cell death might account for this lack of a hyperplasia in the developing CNS of pros mutant embryos. To test this hypothesis, we analyzed the expression of reaper, a gene whose function has been closely associated with initiation of apoptotic cell death (McCall and Steller 1997). We observed higher expression level of reaper in pros mutant embryos (data not shown). An increase in the number of apoptotic cells in 
Figure 1. Increased mitotic activity in the CNS of pros mutant embryos. Mitotic activity in wild type $(A, C, E)$ and homozygous pros mutant $(B, D, F)$ embryos. $(A, B)$ S-phase-specific expression of Histone 1a RNA in the ventral cord of stage-16 wild-type $(A)$ and homozygous pros mutant $(B)$ embryos. $(C, D)$ BrdU incorporation (green) in stage-15 wild-type $(C)$ and pros mutant $(D)$ embryos. Double labeling of embryos with mouse anti-Pros (red) was used to identify homozygous pros mutant embryos. $(E, F)$ Expression of the M-phase-specific marker phospho Histone $\mathrm{H} 3$ (red) in the ventral cords of wild-type $(E)$ and pros mutant $(F)$ embryos. For identification of pros mutant embryos based on their axonal defects, embryos in $E$ and $F$ are double labeled with axon-specific monoclonal antibody BP102 (green). All three cell-cycle markers show a dramatic increase expression in pros mutant embryos $(B, D, F)$ when compared with wild-type embryos $(A, C, E)$. $(G, H)$ Detection of apoptotic cell death using TUNEL assay. $(G)$ TUNEL assay pattern in the ventral cord of a wild-type, stage-16 embryo. $(H)$ The ventral cord of a pros ${ }^{J O 13}$ mutant, stage-16 embryo shows a substantially increased number of labeled cells in TUNEL assay.
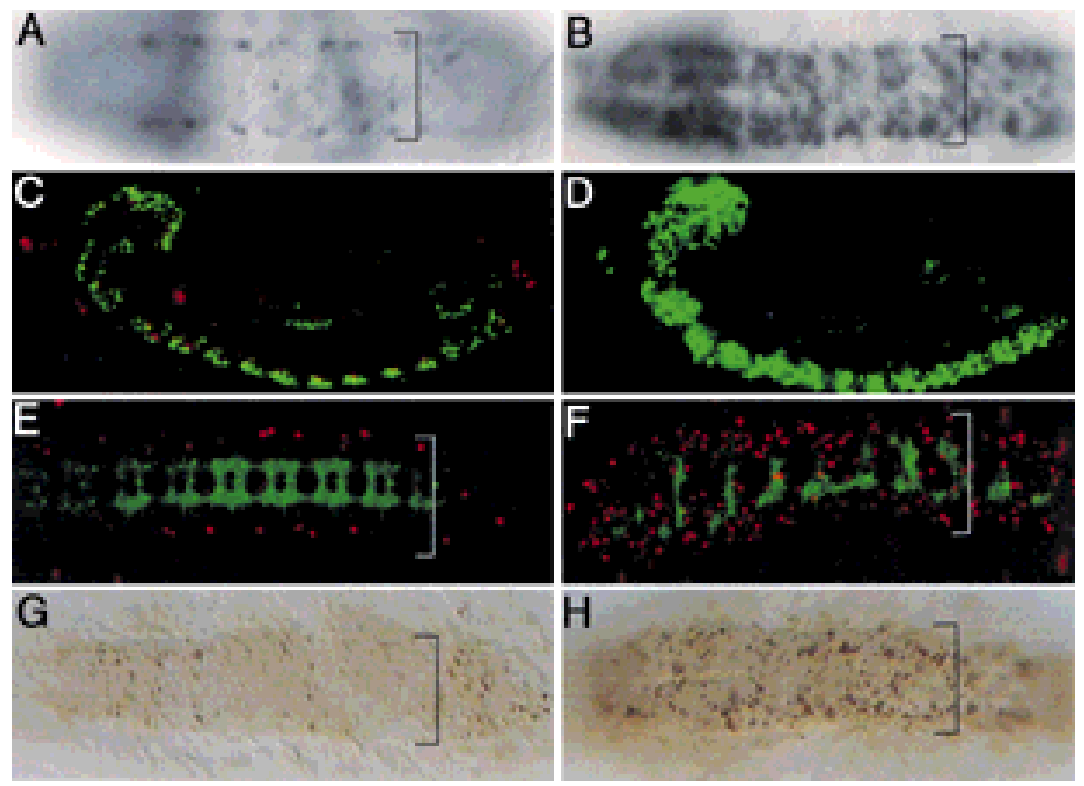

pros mutant embryos was indicated further in TUNEL assays. We observed a substantial increase in the number of labeled cells in pros mutant embryos compared with the wild type (Fig. 1G,H). This suggests that the increased mitotic activity is in part compensated by programmed death of supernumerary cells.

Loss of pros function results in aberrant expression of cell-cycle regulatory genes

Because Pros has been shown previously to be a transcription factor (Hassan et al. 1997), we asked if the ectopic mitotic activity in the CNS of pros mutant embryos is associated with misexpression of cell-cycle regulatory genes. To this end, we examined the RNA expression pattern of several cell-cycle regulatory genes in wild-type and pros mutant embryos. Aberrant expression of cyclin $A$ (cycA) (Lehner and O'Farrell 1989), cyclin $E$ (cycE) (Knoblich et al. 1994), and the Drosophila cdc25 homolog, string (stg) (Edgar et al. 1994), was observed in late-stage pros mutant embryos relative to the wild type (Fig. 2). Therefore, prolonged mitotic activity in pros mutant embryos is associated with continued transcriptional expression of cell cycle regulatory genes.

\section{Ectopic Pros expression suppresses} cell-cycle progression

Ectopic mitotic activity in pros mutants indicates a requirement for Pros activity in the regulation of cell proliferation during neurogenesis. To test this hypothesis, we investigated the consequences of ectopic Pros expres-
Figure 2. Loss of pros function is associated with ectopic RNA expression of cell-cycle regulatory genes. RNA expression of $c y c A, c y c E$, and $s t g$ during late embryogenesis of wild-type $(A, C, E$,$) and homozygous pros mutant (B, D, F$, embryos. $(A, B)$ cycA RNA expression in stage16, wild-type $(A)$ and pros mutant $(B)$ embryos. $(C, D)$ cycE RNA expression in the ventral cord of stage-16, wild-type $(C)$ and pros mutant $(D)$ embryos. $(E, F)$ stg RNA expression in wild-type $(E)$ and pros mutant $(F)$ embryo.
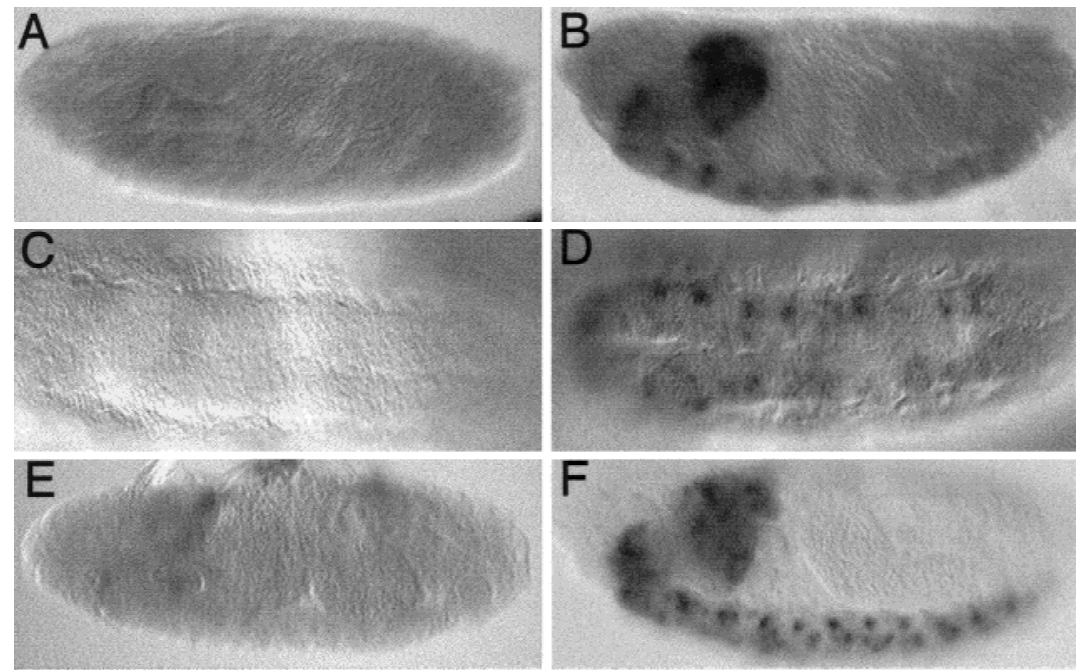
sion on mitotic activity. Full-length Pros was expressed in embryonic tissues using the UAS/GAL4 system (Brand and Perrimon 1993). Ectopic expression of Pros with region-specific driver lines, such as $\mathrm{Kr}-\mathrm{Gal4}$, causes defects that are limited to the region where ectopic Pros expression occurs. In embryos were Pros expression is driven by $\mathrm{Kr}-\mathrm{Gal} 4$, these defects consist of breaks in the developing nervous system (Fig. 3B), as well as reduced epidermal and mesodermal structures (data not show). In addition, little or no Histone 1a RNA expression and

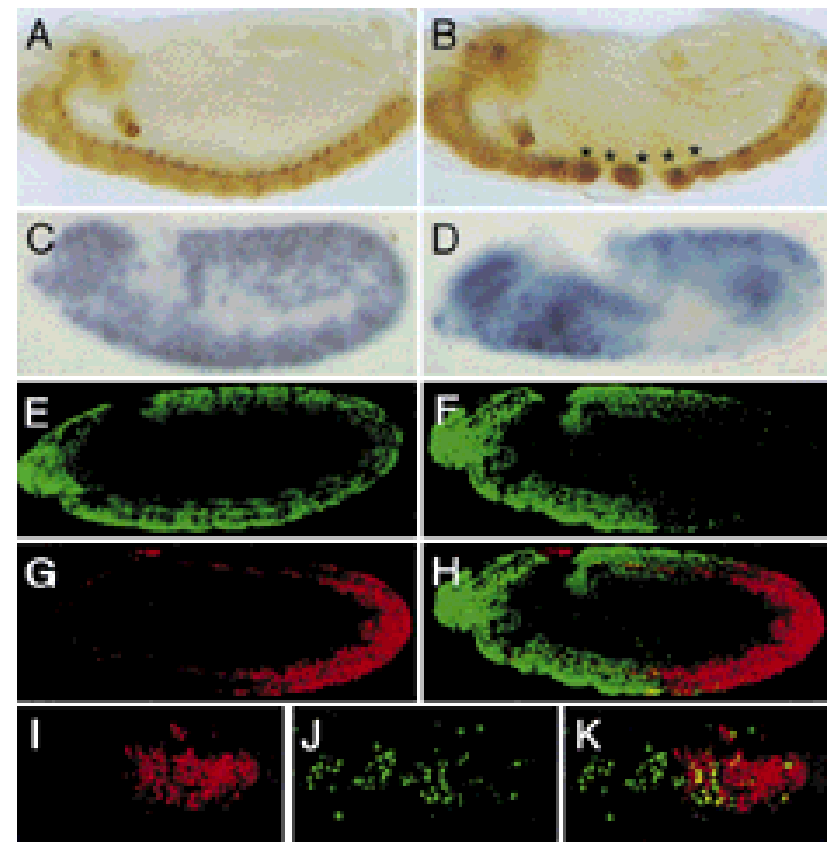

Figure 3. Ectopic Pros expression suppresses cell proliferation. $(A, B)$ CNS of wild-type $(A)$ and Kruppel $(\mathrm{Kr})-\mathrm{Gal} 4 / \mathrm{UAS}-\operatorname{Pros}(B)$ stage-15 embryos stained with anti-HRP. (B) Ectopic expression of Pros within the Kr-domain results in thinning and disruptions of the ventral cord (asterisks). $(C-K)$ Ectopic Pros suppresses mitotic activity. $(C, E)$ Wild-type embryos. $(D, F-K) \mathrm{Kr}$ Gal4/UAS-Pros embryos. These embryos express high levels of Pros protein within the Kruppel domain (labeled in red in panels $G, H, I, K)$. $(C, D)$ RNA expression of the S-phase-specific Histone 1a transcript in wild-type embryo $(C)$ and an embryo with ectopic Pros expression in the $\mathrm{Kr}$-domain $(D)$. Histone 1a RNA expression is suppressed in segments with ectopic Pros expression. $(E, F)$ BrdU incorporation in wild-type $(E)$ and $\mathrm{Kr}-\mathrm{Gal} 4 /$ UAS-Pros $(F)$ embryos. (E) Wild-type embryo with a normal pattern of BrdU incorporation. $(F-H) \mathrm{A} \mathrm{Kr}-\mathrm{Gal} 4 / \mathrm{UAS}-\mathrm{Pros}$ embryo that has been double-labeled for BrdU incorporation $(F$. green) and Pros expression $(G$; red). $(H)$ A merge of $F$ and $G$. Ectopic expression of Pros results in strong suppression of BrdU incorporation. $(I-K)$ Dorsal region of a stage-12 Kr-Gal4/UASPros embryo double labeled with anti-Pros (red) and the M-phase marker anti-phospho Histone H3 (green). (I) Pros expression at the posterior border of the Kr-domain. (J) PhosphoHistone $\mathrm{H} 3$ expression is visible in cells that have entered $\mathrm{M}$ phase. $(K)$ Composite image of $I$ and $J$. Only limited overlap, as indicated by yellow labeling, is evident between cells expressing the M-phase marker (red) and cells with ectopic Pros expression (green). Most of the double-labeled cells are located in the border region of ectopic Pros expression, which has lower levels of ectopic Pros.
BrdU labeling was observed in embryonic domains expressing ectopic Pros (Fig. 3D,F-H), suggesting cells with ectopic Pros do not enter and progress normally through S phase. Furthermore, at embryonic stage 12, suppression of phospho Histone $\mathrm{H} 3$ labeling was evident in regions expressing ectopic Pros (Fig. 3 I-K). In contrast, domains lacking ectopic Pros expression show normal Histone 1a RNA levels, BrdU incorporation, and phospho Histone H3 expression (Fig. 3). The effect of ectopic Pros expression appears to be limited to mitotically active cells, as expression in postmitotic neuronal cells, using the elav-Gal4 driver, does not result in morphologic defects (data not shown).

\section{Ectopic Pros expression results in the transcriptional termination of cell-cycle regulatory gene expression}

To determine whether the premature termination of cell-cycle progression that is associated with ectopic Pros expression results in misexpression of cell-cycle regulatory genes, we analyzed the RNA expression of several cell-cycle regulatory genes: stg, RBF (Du et al. 1996), E2F (Duronio et al. 1995), cycE, and cycA. Strong reductions in the transcript levels of these genes were observed in regions expressing ectopic Pros (Fig. 4). To understand whether the reduction of cell-cycle regulatory gene transcripts is regulated at the transcriptional or post-transcriptional level, we examined the expression of $l a c Z$ reporter gene of enhancer trap lines for $c y c A$ $\left(c y c A^{03946}\right)$ and $E 2 F\left(E 2 F^{07172}\right)$. Using these lines, we observed a suppression of reporter gene expression that corresponded with ectopic Pros expression (Fig. $4 \mathrm{H}$ and data not shown), indicating the observed reduction in transcript level appears to result from transcriptional suppression, rather than from post-transcriptional events. Importantly, ectopic Pros expression did not result in a general shutdown of transcription, as analysis of an array of developmental genes, including runt, hunchback (Fig. 4I and N), Kruppel, fushi tarazu, even-skipped, engrailed, and elav (Bier et al. 1988) (data not shown), revealed normal expression levels in regions expressing ectopic Pros. These results point to a rather specific suppression of cell-cycle regulatory genes, and suggest that the suppression of mitotic activity caused by ectopic Pros activity is attributable to the transcriptional suppression of cell-cycle regulatory genes.

Our results suggest a model in which Pros functions to stop transcriptional expression of multiple cell cycle regulatory genes in cells entering their final mitotic division in the developing CNS. Localization of Pros to the cytoplasmic membrane of neuroblasts permits these cells to express cell-cycle regulatory genes and stay mitotically active. Partitioning and translocation of Pros to the GMC nucleus results in transcriptional termination of multiple cell-cycle regulatory genes, which effectively limits the capacity of a cell to undergo additional rounds of mitotic divisions. Pros-mediated transcriptional termination of cell-cycle regulatory genes would allow completion of the last division through use of previously transcribed and/or translated gene products. New mi- 


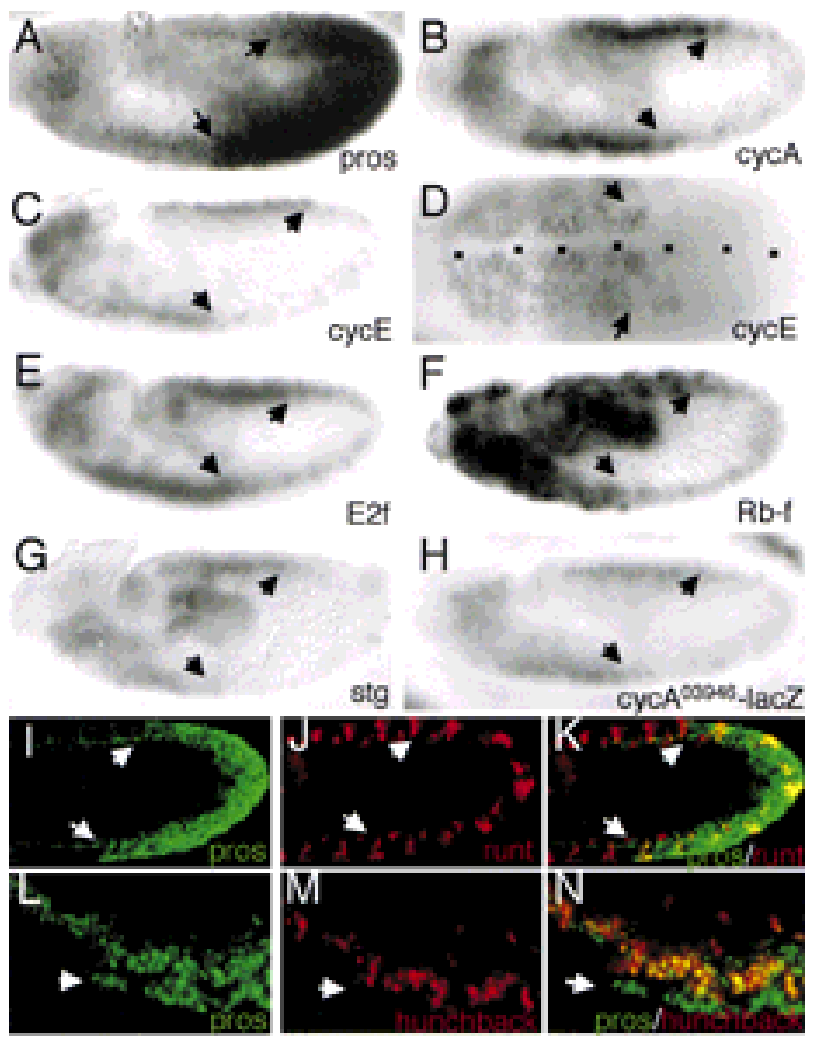

Figure 4. Ectopic Pros suppresses the RNA expression of critical cell-cycle regulatory genes. (A) Kr-Gal4/UAS-Pros embryo labeled with anti-Pros. High levels of ectopic Pros are expressed in the Kruppel domain, marked by arrows. $(B-G)$ RNA expression of $c y c A(B), \operatorname{cyc} E(C$, lateral view; $D$, dorsal view), E2F $(E)$, $R B F(F)$, and stg $(G)$. A strong reduction, or complete absence, of RNA expression of these cell-cycle regulatory genes is evident in regions with ectopic Pros expression (arrows). (H) RNA expression of the enhancer trap line $c y c A^{03946}-1 a c Z$ reporter gene in a $\mathrm{Kr}-\mathrm{Gal}$ /UAS-Pros embryo. A strong reduction in lacZ RNA levels is evident in central region of the embryo expressing ectopic Pros. $(I-N)$ Ectopic Pros expression does not result in a general suppression of gene expression. Ectopic expression of Pros $(I, L)$ does not result in suppression of runt $(J, K)$ or hunchback $(M, N)$ expression. White arrows in panels $I-N$ mark the borders of the central region with ectopic Pros expression.

totic cycle, however, could not be initiated. The role of Pros in setting up GMCs to exit from a mitotically active state correlates well with previous observations showing that the cdk inhibitor gene dacapo (dap), is expressed and required in cells before undergoing their final division (de Nooij et al. 1996; Lane et al. 1996). In wild-type embryos, dap is expressed transiently in GMCs, which also contain nuclear Pros. The activities of nuclear Pros and Dap may function in concert to prohibit further cell proliferation. While Dap inhibits CDK2/cycE kinase activity, and thereby promotes G1 arrest, nuclear Pros stops transcription of critical cell-cycle regulatory genes. Pros, however, may not function exclusively in parallel to Dap. Pros activity is required for the termination of the expression of deadpan (dpn), a gene encoding a panneural bHLH protein (Vaessin et al. 1991). Dpn itself functions as a suppressor of dap expression in the larval brain (Wallace et al. 2000). The requirement of Pros to suppress a negative regulator of Dap expression suggests that Pros may also have a role in the activation of dap expression.

It is possible that the transcriptional suppression of cell-cycle regulatory genes by Pros is mediated independently for individual genes, or caused by suppression of a single transcriptional regulator such as E2F. Alternatively, it could represent a secondary consequence of cell-cycle suppression. Loss of E2F function has been shown in Drosophila to result in the loss of cycE gene expression, as well as defects in cell proliferation during late stages of embryogenesis (Duronio and O'Farrell 1995; Duronio et al. 1995). Loss of Drosophila E2F function, however, does not affect $c y c E$ expression in the developing CNS (Duronio and O'Farrell 1995). In addition, in E2F mutant embryos, tissues outside the nervous system exhibit changes in $c y c E$ expression later (Duronio et al. 1995/ than changes caused by ectopic Pros expression. Therefore, suppression of E2F expression alone is insufficient to explain the suppression of $c y c E$ expression. Loss of cell-cycle regulatory gene expression as a secondary consequence of a block in cell-cycle progression is also unlikely. During Drosophila embryogenesis, RNA expression of cell-cycle regulatory genes is not directly linked to cell-cycle progression, as cell-cycle arrest does not interfere with the transcription of Drosophila cycE or stg (Lehman et al. 1999).

Loss of pros gene function has previously been associated with severe defects in axonal outgrowth (Doe et al. 1991; Vaessin et al. 1991), as well as other developmental defects. The observation of increased cell proliferation and apoptotic cell death in the developing nervous system raises the possibility that some previously described phenotypes could be a consequence of the increased cell number and/or increased apoptotic cell death in pros mutant animals. Our data presently do not allow us to distinguish whether all neuronal lineages undergo additional rounds of cell proliferation, or how many additional rounds of mitotic division occur. Analysis of the mitotic division pattern of individual GMCs in pros mutant animals will be critical for the understanding of the neuronal phenotypes associated with the loss of pros function.

The role of Pros in regulating mitotic activity is unlikely to be limited to Drosophila. Expression of Drosophila Pros and the mouse Pros homolog Prox1 in mammalian cell lines results in strong growth inhibition of transfected cells (L. Li and H. Vaessin, unpubl.). In addition, expression of the murine Prox 1 has been observed in cells that stop dividing and enter neuronal differentiation (Torii et al. 1999). Mammalian Pros homologs, therefore, may have a similar role in cell-cycle regulation during mammalian development.

\section{Materials and methods}

Drosophila stocks and genetic crosses

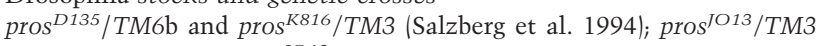
(Vaessin et al. 1991). pros $^{J O 13}$ carries a deletion of the $5^{\prime}$ region of the pros 
transcription unit and is protein null (Vaessin et al. 1991). The molecular basis of the mutation associated with pros ${ }^{D 135}$ and pros $^{K 816}$ is presently not known. All three pros alleles are classified as amorphic mutations based on the observation, that they do not produce detectable levels of Pros protein, and result in an neuronal phenotype in homozygous mutant embryos that is comparable in strength with the phenotype caused by a deletion of pros $\left(D f(3 R) M^{K X 1}\right)$. All three alleles were used to determine the effects of loss of pros function on mitotic activity. In this analysis, homozygous pros mutant embryos were identified based on the lack of pros expression using anti-Pros, or the axonal defects associated with loss of pros function (Doe et al. 1991; Vaessin et al. 1991) using BP102 monoclonal antibody. Ectopic expression of full-length Pros was achieved through crossing UAS-Pros flies (Manning and Doe 1999) to various Gal4 driver lines. The following Gal4 driver lines were used in this analysis: Kruppel-Gal4; da-Gal4; elav-Gal4. Ectopic expression of Pros was verified with anti-Pros (Vaessin et al. 1991).

In situ hybridization, BrdU incorporation analysis, TUNEL assay, and immunohistochemistry

In-situ hybridization was performed as described previously (Vaessin et al. 1991) using digoxygenin-labeled anti-sense RNA probes and alkaline phosphatase-conjugated anti-Dig antibodies. BrdU incorporation assay was performed as described in Bodmer et al. (1989), and TUNEL assays were performed as described in Hassan and Vaessin (1997) using the Boehringer Mannheim In situ Cell Death Detection Kit. Immunohistochemistry was performed as described previously (Vaessin et al. 1991). Confocal microscopy was performed using a Biorad MRC1024 system.

\section{Acknowledgments}

We thank Drs. Mazusaki and Doe for UAS-Pros lines; Drs. Edgar, Lehner, Duronio, and Dyson for providing cDNA clones of $s t g, c y c E, E 2 F$, and $R b$; Drs. Doe, Jan, Kosman, and Seeger for antibodies; Drs. Bellen and Salzberg for EMS-induced pros alleles; and the Bloomington Drosophila Stock Center for various Drosophila stocks. We also thank Drs. Hai, Leone, and Seeger for many helpful comments. This work was supported by grants from the National Science Foundation and Ohio Cancer Research Associates to H.V.

The publication costs of this article were defrayed in part by payment of page charges. This article must therefore be hereby marked "advertisement" in accordance with 18 USC section 1734 solely to indicate this fact.

\section{References}

Bier, E., L. Ackerman, S. Barbel, L. Jan, and Y.N. Jan. 1988. Identification and characterization of a neuron-specific nuclear antigen in Drosophila. Science 240: 913-916.

Bodmer, R., R. Carretto, and Y.N. Jan. 1989. Neurogenesis of the peripheral nervous system in Drosophila embryos: DNA replication patterns and cell lineages. Neuron 3: 21-32.

Brand, A.H. and N. Perrimon. 1993. Targeted gene expression as a means of altering cell fates and generating dominant phenotypes. Development 118: 401-415.

Chu-Lagraff, Q., D.M. Wright, L.K. McNeil, and C.Q. Doe. 1991. The prospero gene encodes a divergent homeodomain protein that controls neuronal identity in Drosophila. Development 2: 79-85.

de Nooij, J.C., M.A. Letendre, and I.K. Hariharan. 1996. A cyclin-dependent kinase inhibitor, Dacapo, is necessary for timely exit from the cell cycle during Drosophila embryogenesis. Cell 87: 1237-1247.

Doe, C.Q., Q. Chu-LaGraff, D.M. Wright, and M.P. Scott. 1991. The prospero gene specifies cell fates in the Drosophila central nervous system. Cell 65: 451-464.

Du, W., M. Vidal, J.E. Xie, and N. Dyson. 1996. RBF, a novel RB-related gene that regulates E2F activity and interacts with cyclin E in Drosophila. Genes \& Dev. 10: 1206-1218.

Duronio, R.J. and P.H. O'Farrell. 1995. Developmental control of the G1 to $\mathrm{S}$ transition in Drosophila: Cyclin Eis a limiting downstream target of E2F. Genes \& Dev. 9: 1456-1468.

Duronio, R.J., P.H. O'Farrell, J.E. Xie, A. Brook, and N. Dyson. 1995. The transcription factor E2F is required for S phase during Drosophila embryogenesis. Genes \& Dev. 9: 1445-1455.
Edgar, B.A. and C.F. Lehner. 1996. Developmental control of cell cycle regulators: A fly's perspective. Science 274: 1646-1652.

Edgar, B.A., D.A. Lehman, and P.H. O'Farrell. 1994. Transcriptional regulation of string (cdc25): A link between developmental programming and the cell cycle. Development 120:3131-3143.

Hassan, B. and H. Vaessin. 1997. Daughterless is required for the expression of cell cycle genes in peripheral nervous system precursors of Drosophila embryos. Dev. Genet. 21: 117-122.

Hassan, B., L. Li, K.A. Bremer, W. Chang, J. Pinsonneault, and H. Vaessin. 1997. Prospero is a panneural transcription factor that modulates homeodomain protein activity. Proc. Natl. Acad. Sci. 94: 1099110996.

Hirata, J., H. Nakagoshi, Y. Nabeshima, and F. Matsuzaki. 1995. Asymmetric segregation of the homeodomain protein Prospero during Drosophila development. Nature 377: 627-630.

Jacobs, J.R. 1993. Perturbed glial scaffold formation precedes axon tract malformation in Drosophila mutants. J. Neurobiol. 24: 611-626.

Jan, Y.N. and L.Y. Jan. 1998. Asymmetric cell division. Nature 392: 775778.

Kauffmann, R.C., S. Li, P.A. Gallagher, J. Zhang, and R.W. Carthew. 1996. Ras1 signaling and transcriptional competence in the R7 cell of Drosophila. Genes \& Dev. 10: 2167-2178.

Knoblich, J.A., K. Sauer, L. Jones, H. Richardson, R. Saint, and C.F. Lehner. 1994. Cyclin E controls S phase progression and its down-regulation during Drosophila embryogenesis is required for the arrest of cell proliferation. Cell 77: 107-120.

Knoblich, J.A., L.Y. Jan, and Y.N. Jan. 1995. Asymmetric segregation of Numb and Prospero during cell division. Nature 377: 624-627.

Lane, M.E., K. Sauer, K. Wallace, Y.N. Jan, C.F. Lehner, and H. Vaessin. 1996. Dacapo, a cyclin-dependent kinase inhibitor, stops cell proliferation during Drosophila development. Cell 87: 1225-1235.

Lehman, D.A., B. Patterson, L.A. Johnston, T. Balzer, J.S. Britton, R. Saint, and B.A. Edgar. 1999. Cis-regulatory elements of the mitotic regulator, string/Cdc25. Development 126: 1793-1803.

Lehner, C.F. and P.H. O'Farrell. 1989. Expression and function of Drosophila cyclin A during embryonic cell cycle progression. Cell 56: $957-968$.

Manning, L. and C.Q. Doe. 1999. Prospero distinguishes sibling cell fate without asymmetric localization in the Drosophila adult external sense organ lineage. Development 126: 2063-2071.

Matsuzaki, F., K. Koizumi, C. Hama, T. Yoshioka, and Y. Nabeshima. 1992. Cloning of the Drosophila prospero gene and its expression in ganglion mother cells. Biochem. Biophys. Res. Commun. 182: 13261332.

McCall, K. and H. Steller. 1997. Facing death in the fly: Genetic analysis of apoptosis in Drosophila. Trends Genet. 13: 222-226.

Salzberg, A., D. D'Evelyn, K.L. Schulze, J.K. Lee, D. Strumpf, L. Tsai, and H.J. Bellen. 1994. Mutations affecting the pattern of the PNS in Drosophila reveal novel aspects of neuronal development. Neuron 13: $269-287$.

Spana, E.P. and C.Q. Doe. 1995. The prospero transcription factor is asymmetrically localized to the cell cortex during neuroblast mitosis in Drosophila. Development 121: 3187-3195.

Torii, M., F. Matsuzaki, N. Osumi, K. Kaibuchi, S. Nakamura, S. Casarosa, F. Guillemot, and M. Nakafuku. 1999. Transcription factors Mash-1 and Prox-1 delineate early steps in differentiation of neural stem cells in the developing central nervous system. Development 126: 443-456.

Vaessin, H., E. Grell, E. Wolff, E. Bier, L.Y. Jan, and Y.N. Jan. 1991. Prospero is expressed in neuronal precursors and encodes a nuclear protein that is involved in the control of axonal outgrowth in Drosophila. Cell 67: 941-953.

Wallace, K., T.-H. Liu, and H. Vaessin. 2000. The Pan-neural bHLH proteins Deadpan and Asense regulate mitotic activity and cdk inhibitor dacapo expression in the Drosophila larval optic lobes. genesis (in press).

Zavitz, K.H. and S.L. Zipursky. 1997. Controlling cell proliferation in differentiating tissues: Genetic analysis of negative regulators of G1 $\rightarrow$ S-phase progression. Curr. Opin. Cell Biol. 9: 773-781. 


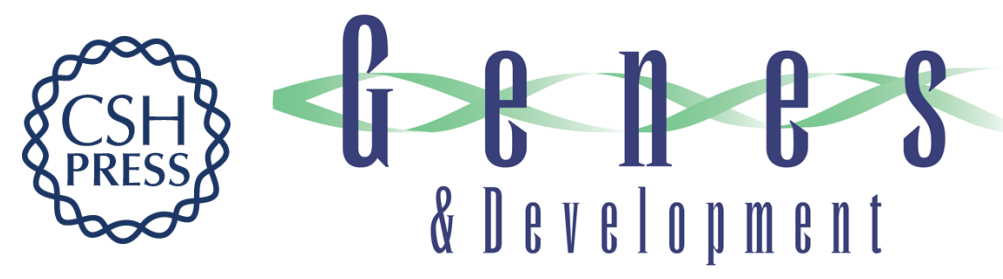

\section{Pan-neural Prospero terminates cell proliferation during Drosophila neurogenesis}

Ling Li and Harald Vaessin

Genes Dev. 2000, 14:

Access the most recent version at doi:10.1101/gad.14.2.147

References This article cites 29 articles, 13 of which can be accessed free at: http://genesdev.cshlp.org/content/14/2/147.full.html\#ref-list-1

License

Email Alerting

Receive free email alerts when new articles cite this article - sign up in the box at the top Service right corner of the article or click here.

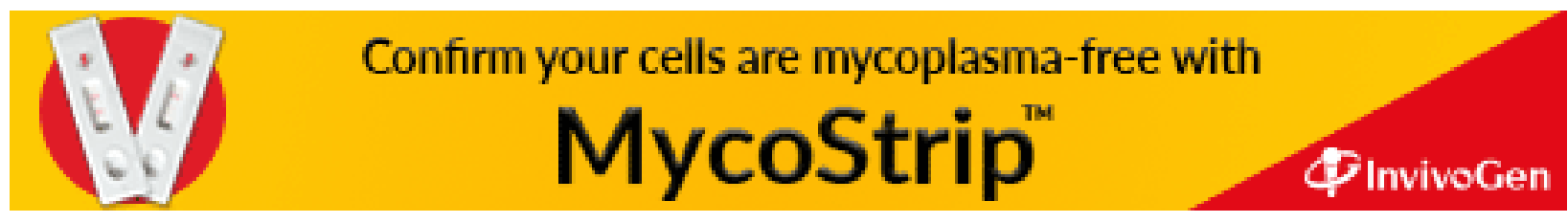

